\title{
"Tropospheric $\mathrm{NO}_{2}$ vertical column densities over Beijing: results of the first three years of ground-based MAX-DOAS measurements (2008-2011) and satellite validation" published in Atmos. Chem. Phys., 13, 1547-1567, 2013
}

\author{
J. Z. Ma ${ }^{1}$, S. Beirle ${ }^{2}$, J. L. Jin ${ }^{1,{ }^{*}}$, R. Shaiganfar ${ }^{2}$, P. Yan ${ }^{1, *}$, and T. Wagner ${ }^{2}$ \\ ${ }^{1}$ Chinese Academy of Meteorological Sciences, Beijing, China \\ ${ }^{2}$ Max Planck Institute for Chemistry, Mainz, Germany \\ *now at: CMA Meteorological Observation Centre, Beijing, China
}

Correspondence to: J. Z.Ma (mjz@cams.cma.gov.cn)

There was a typing error for the line legend of Fig. 13. The correct figure is shown below.

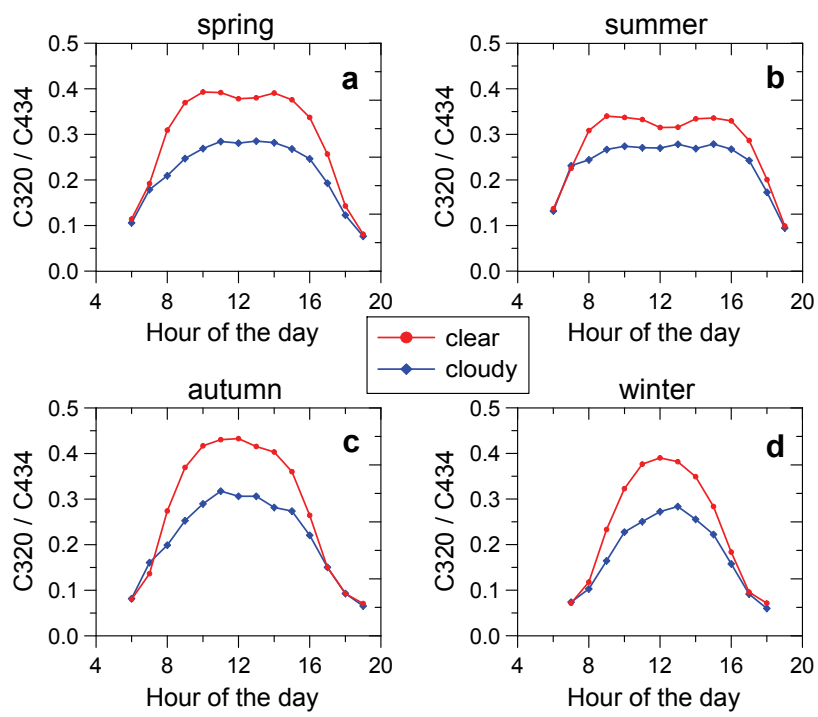

Fig. 13. Diurnal variations of the $\mathrm{C} 320 / \mathrm{C} 434$ ratio under clear and cloudy conditions, averaged for different seasons from August 2008 to September 2011.

Published by Copernicus Publications on behalf of the European Geosciences Union. 